\title{
Even if it might not be true, evidence cannot be false
}

\author{
Clayton Littlejohn ${ }^{1}$ (D) $\cdot$ Julien Dutant $^{2}$
}

Accepted: 29 June 2021 / Published online: 9 July 2021

(C) The Author(s) 2021

\begin{abstract}
Wordly internalists claim that while internal duplicates always share the same evidence, our evidence includes non-trivial propositions about our environment. It follows that some evidence is false. Worldly internalism is thought to provide a more satisfying answer to scepticism than classical internalist views that deny that these propositions about our environment might belong to our evidence and to provide a generally more attractive account of rationality and reasons for belief. We argue that worldly internalism faces serious difficulties and that its apparent advantages are illusory. First, it cannot adequately handle some not terribly strange cases of perceptual error. Second, it cannot explain why one should plan to use their evidence to update their beliefs. The second issue allows us to explain why cases of misplaced certainty do not require us to introduce false evidence into our views and that why the alleged advantage of worldly internalism in resisting sceptical pressures is illusory.
\end{abstract}

Keywords Evidence $\cdot$ Epistemic rationality $\cdot$ Epistemic internalism

\section{Even if it might not be true, evidence cannot be false}

Internalists about evidence ('internalists' hereafter) believe that internal duplicates necessarily have the same evidence. While many internalists have held that our evidence is constituted by the states of mind we share in common with our internal

Clayton Littlejohn

cmlittlejohn@gmail.com

Julien Dutant

Julien.dutant@kcl.ac.uk

1 Dianoia Insitute of Philosophy, Australian Catholic University, Melbourne, Australia

2 King's College London, London, England 
duplicates (e.g., our experiences, apparent memories, intuitions, etc.), worldly internalists claim that our evidence includes (non-trivial) propositions about our environment. They think that when we have the experience as of, say, a red, bulgy tomato, our evidence might include propositions that will be true iff there is something before us that is red, that it is bulgy, or (perhaps) is a tomato. To reconcile the idea that our evidence might entail that there is something 'outside' the mind that is red, that is bulgy, or that is a tomato with internalism, worldly internalists embrace the idea that a worldly proposition might be evidence even if it is false. Traditional internalists, by contrast, don't have to recognise the possibility of false evidence because they can either characterise our evidence as consisting of (true) propositions about our own mental lives or propose that our evidence is constitutes by mental states or events rather than the propositions that capture their contents. We shall argue that worldly internalism faces some serious difficulties because of its reliance on false evidence (i.e., false propositions about the properties of mind-independent objects that constitute part of a thinker's evidence). First, the view cannot adequately handle some not terribly strange cases of perceptual error. Second, it cannot explain why one should plan to use their evidence to update their beliefs. The second issue allows us to explain why cases of misplaced certainty do not require us to introduce false evidence into our views and that why the alleged advantage of worldly internalism in resisting sceptical pressures is illusory. As we see it, it might be wise for internalists to embrace a view of evidence on which evidence is something that is (strictly speaking) neither capable of being true or being false (e.g., a view on which it is constituted by states of mind or mental events instead of propositions).

\section{Introduction}

According to Williamson (2000), all evidence is knowledge, and all knowledge is evidence. If we can agree that the scope of our knowledge extends beyond the things that we might know if, say, we were brains in vats, his identification of evidence and knowledge (' $\mathrm{E}=\mathrm{K}$ ' hereafter) would commit us to the view that our evidence likewise goes beyond the evidence we could have if we were brains in vats (assuming, of course, that we are not). This idea that our evidence might go beyond theirs troubles quite a few epistemologists. If nothing else, it might seem that our beliefs are just as justified as theirs are and that the attitudes that it would be rational for us to have are the attitudes that it would be rational for them to have. It's not hard to see why this would be if we shared the same evidence. It's harder to see why this would be if our evidence differs significantly from theirs. ${ }^{1}$

\footnotetext{
${ }^{1}$ See Cohen (1984) for an initial presentation of this idea where the target is reliabilism but the sameness of evidence assumption is operative. See Silins (2005) and Wedgwood (2002) for more recent discussion that engages with $\mathrm{E}=\mathrm{K}$. For attempts to reconcile the intuition that the same attitudes are rational for us with a view on which our evidence differs, see Fratantonio and McGlynn (2018), Ichikawa (2014), Kiesewetter (2017), and Lord (2018).
} 
Internalists about evidence ('internalists' hereafter) believe that if two thinkers are in the same non-factive mental states, they'll have the same evidence and that this is so even if they happen to be embedded in different environments (e.g., that we are in a normal situation and some of our counterparts are embedded in environments in which malign forces conspire against them). Upon pain of scepticism, internalists have to reject $\mathrm{E}=\mathrm{K}$, but their rejection of $\mathrm{E}=\mathrm{K}$ only tells us what they think evidence isn't. It's good to know what evidence isn't, but it would be better to know what it is.

In some initial responses to Williamson, some internalists defended the view that a thinker's evidence is constituted by some of the thinker's non-factive mental states and events. McCain, for example, proposed this:

Your experience of being in pain is evidence for you that you are in pain. Your experience of being hungry is evidence for you that you are hungry. Your experience of a book looking blue is evidence for you that the book is blue (2014: 19).

We find similar proposals about experience and evidence in Brueckner (2009) and Conee and Feldman (2004). Notice that this view differs from Williamson's on two key points. On Williamson's view, a thinker's evidence must be veridical and it might be world-implicating. A thinker's evidence is world-implicating if it includes some propositions that entail that certain propositions about the existence of and properties of mind-independent objects are true. It is veridical if propositionally specified evidence is limited to truths (i.e., facts or true propositions). On this classical internalist view, the thinker's evidence is not world-implicating because it consists of the thinker's experiences (e.g., feelings of hunger, the experience of a book looking a certain way, etc.) or facts about the thinker's non-factive mental states and events, not propositions about the things that we encounter in experience (e.g., tomatoes, tables, books, shadows, etc.). To be sure, experiences might be about mind-independent objects and their properties, but so long as they do not constitutively involve them, the classical internalist maintains that neither the evidence nor a complete description of it would entail that, say, a tomato is present, that it is red and bulgy, etc. Thus, the classical internalist's evidence is not worldimplicating. And if this evidence consists of things like experiences, sensations, or seemings, it consists of states of mind or mental events and is not, in our sense, veridical. Experience is not itself true or false. ${ }^{2}$

In more recent work, internalists have started to break away from classical internalism and embrace views on which evidence is world-implicating. Rather than identify a thinker's evidence with her experiences, worldly internalists identify a thinker's evidence with propositions that are about the things that we seem to encounter in our experiences. Rather than say that the experience you might have when looking at a blue book is evidence that the book exists or that it has a certain colour, the worldly internalists will say (depending upon which one you ask) that

\footnotetext{
${ }^{2}$ Of course, experiences might be veridical in a more familiar sense if they are accurate. Remember that veridicality in our stipulated sense is a matter of something being true nd so it is limited to truths (e.g., true propositions or facts).
} 
your evidence is that the book looks blue, that the book is blue, or that you see that the book is blue. In each instance, the evidence would be constituted by a proposition that is true only if some mind-independent object exists and has some property (e.g., the property of having a certain look, the property of having a certain colour, the property of being seen by someone etc.). It might seem at first that evidence being world-implicating is in tension with internalism. How could it be, say, that my evidence entails that a mind-independent object like a tomato or a book exist if my evidence is nothing beyond the evidence I could have if I were a brain in a vat?

Any tension here between internalism and the idea that evidence might be worldimplicating is merely apparent. If evidence doesn't have to be true and we drop the veridicality requirement, we can allow that a proposition that entails certain nontrivial truths about the external world might be included in someone's evidence. In the good case, this piece of evidence would be, say, a proposition (which would be true) that would entail that a tomato is present and red and bulgy. In the bad, this same proposition would still be a piece of evidence even though it were false. It would still entail that a tomato is present and red and bulgy (e.g., if it is the proposition that this is a red and bulgy tomato, it would entail itself regardless of whether it was true or false). The key to accommodating world-implicating evidence for the internalist is to allow for false evidence, evidence that is genuinely evidence and so does the things that evidence has to do that consists of false propositions. $^{3}$

The question that interests us is a question that should interest internalists. Should internalists embrace worldly internalism and reject the idea that evidence has to be veridical to be evidence? Might it be advisable instead for internalists to defend some form of classical internalism and restrict evidence to things like non-factive mental states and events (or, perhaps, facts about such mental states and events). We think that the issue is complex. There are interesting and prima facie plausible arguments for thinking that a thinker's evidence might be world-implicating, but we also think that worldly internalism faces significant difficulties that do not seem to arise for classical internalism.

\section{Worldly internalism}

If we ask the internalists to tell us what my evidence might be for thinking that someone has recently been to the market, they might say that it's my experience as of fresh tomatoes or blood oranges on the kitchen counter. This is what a classical internalist would say. They might say that it's a seeming (e.g., it seems that there are

\footnotetext{
${ }^{3}$ For previous defences of the possibility of false evidence, see Arnold (2013), Comesaña and Kantin (2010), Comesaña (2015, 2020a, 2020b), Drake (2018), Fantl (2015), Rizzieri (2011), Shaffer (2015), and Schroeder (2008, 2021a). For defences of the veridicality of evidence, see Littlejohn $(2012,2013)$ and Williamson (2000).
} 
fresh tomatoes in the basket). Another thing a classical internalist might say. A worldly internalist might say things like this. It is that these pieces of fruit look fresh (e.g., Comesaña \& McGrath, 2016). It is that these pieces of fruit are fresh. It is that I see that these pieces of fruit are fresh (e.g., Schroeder, 2021a, b). These are things that worldly internalists might say. In each instance, the evidence offered is identified as a proposition that is true only if some pieces of fruit exist and have certain properties (e.g., the property of having the look of a fresh piece of fruit, the property of being a fresh piece of fruit, etc.). On the worldly internalist view, the evidence is the kind of thing that could be said to be true or false, the kind of thing that entails other things and can be entailed by other things, and the things that are the objects of attitudes like belief and thus good candidates for things that figure in theoretical reasoning.

It might seem that arguments for thinking of evidence as consisting of propositions or facts would count in favour of the worldly internalist view, but the classical internalist might say with some justice that their view could accommodate the (alleged) propositionality of evidence as well, provided that it restricts the propositions that constitute evidence to ones that are about things like experiences, appearances, seemings, and so on. We think classical internalists can reasonably ask whether there are good reasons for thinking that our evidence might be both propositional and world-implicating as we don't think that the propositionality of evidence itself is something that has to trouble a classical internalist.

Why do worldly internalists believe that our evidence is world-implicating? We think that there are at least two rationales for the view, one that has to do with propositional justification and the other that has to do with doxastic justification. The first has to do with the perceived inadequacy of the classical internalist's approach to justification. We'll discuss this further in $\S 4$, but the root worry is that the classical internalist's candidate evidence is not a 'strong enough' reason to justify beliefs that all parties agree would be justified. As Comesaña and McGrath put it, they do not see how "facts about phenomenal character ... weigh at all in favor in believing one or another proposition about the world outside us", saying that they have the wrong "subject matter" to do so (2016: 997). This fits with an idea, defended elsewhere by Comesaña, that the subject matter of supporting considerations and the considerations they genuinely support must mesh appropriately so that, "a set of propositions $\mathrm{S}$ supports a further proposition $p$ only if, collectively, the propositions in $\mathrm{S}$ have the same subject matter as $p$ " (2015: 89). We think that there are important dialectical considerations to consider here, but we think that a careful examination of this concern should wait until after we discuss evidence and updating. Ultimately, we shall argue that there is little reason to think that worldly internalism fares much better than classical internalism in explaining how the evidence offered by experience justifies beliefs about the existence of and properties of external objects. Concerns about the adequacy of evidence on the classical internalist conception should arise for the worldly internalist's conception of evidence, too. 
Comesaña and McGrath also suggest that considerations about basing support worldly internalism over classical internalism. ${ }^{4}$ They write:

... we do not normally (if ever) form our perceptual beliefs on the basis of considerations having to do with our mental states. Moore's observations on what has come to be called the "transparency of experience", are relevant here. We "see through" our phenomenal states, our attention is normally focused on the outside world, not on the mental states through which that world is revealed to us. But for [classical internalism] these mental states would need to be part of the basis, if the resulting belief is to be justified (2016: 999).

The previous concern about whether the classical internalist's evidence provides adequate support would seem to be one about propositional or ex ante justification and this seems to be a concern about doxastic justification. If, as it seems, we do not base our perceptual beliefs on considerations about experiences themselves, how might our perceptual beliefs be doxastically justified or how might they have ex post justification if the evidence that justifies these beliefs is either constituted by the experiences or considerations about them?

We agree that there is a non-trivial issue here for the classical internalists to deal with, but we also don't see this as a decisive problem for classical internalists. As the McCain quotation illustrates above, some classical internalists think that our perceptual beliefs are based on experiences rather than propositions. He would presumably agree that we do not form our perceptual beliefs on the basis of considerations about our mental states but would not conclude from this that we form them on the basis of propositions about worldly entities. These issues about whether all justified beliefs must be based on propositions are complex. We think they take us beyond the scope of this paper where our aim is to argue that worldly internalists face problems with their theory of propositional justification. If our arguments are correct, they arise for worldly internalists because of their distinctive commitment to false evidence. While we don't propose to solve the basing problems for classical internalists here, we think that readers might be interested to learn that embracing a worldly internalist view that provides a better account of basing comes with a distinctive set of problems. It's to these problems that we shall now turn.

\section{Rationality and evidential consistency}

Worldly internalists say that in paradigmatic cases in which you have a visual experience as of $p$, your evidence includes $p$, or that you see that $p$, or that it looks as if $p$. (Remember that for the worldly internalists $p$ being evidence does not require $p$ to be true and that $p$ is understood in such a way that the truth or falsity of $p$ depends, in part, upon matters that do not supervene upon our non-factive mental states.) In slightly less paradigmatic cases, one may have a visual experience as of

\footnotetext{
4 An anonymous referee for this journal raised the concern that we had not discussed this rationale in a previous draft.
} 
$p_{1}, \ldots, p_{n}$ where these propositions are inconsistent (and recognizably so). ${ }^{5}$ Consider a Penrose triangle:

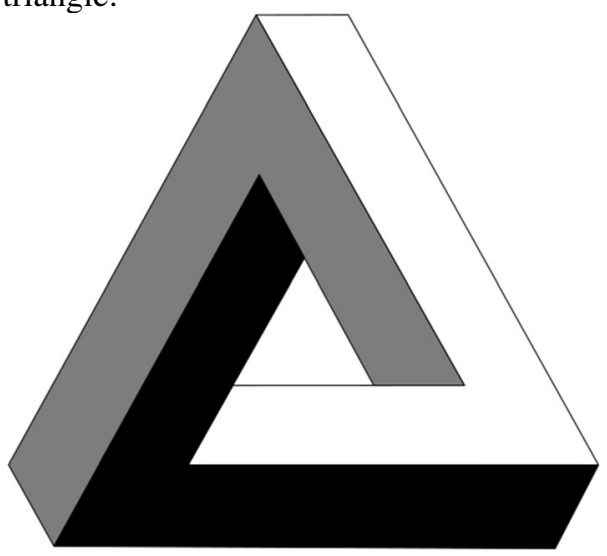

It visually seems that the left side is closer than the bottom one, that the bottom side is closer than the right one, and that the right side is closer than the left one. ${ }^{6}$ Should worldly internalists also say that in some cases, the evidence provided by our experiences is inconsistent? Let's consider both options.

\subsection{If Inconsistent evidence is possible}

Suppose first that they allow that it's possible in some case for a thinker's evidence to be inconsistent (e.g., when we have experiences with inconsistent contents). Let's take the case of the Penrose triangle as our example and suppose that it shows that the worldly internalist has to embrace the following thesis:

Inconsistent Evidence: A thinker's evidence might be constituted by an inconsistent set of worldly propositions. ${ }^{7}$

\footnotetext{
${ }^{5}$ Some contributors to these discussions (e.g., Comesaña (2020b: 133)) are wary of consistency or closure constraints that require logical omniscience. They'll say, for instance, that it is not irrational to have inconsistent beliefs if one is unable to recognize the inconsistency. Below we restrict our attention to cases where the relevant logical relations are obvious to the agents concerned.

${ }^{6}$ That is not literally true when the figure is presented on paper, since we can visually tell that it is a flat drawing. But there are sculptures of the Penrose triangle that will produce the paradoxical experience when seen from the right angle. See Williamson (2009: 310) for an analogous case used against a different account of evidence.

7 Worldly internalists don't share some single view about which propositions belong to our evidence, so they don't agree on what the inconsistent body of evidence would be. It could be inconsistent propositions about the way that different things look, inconsistent propositions about other properties that these objects have/lack, or inconsistent propositions about what it is that the subject sees. They might also disagree about the case of the Penrose triangle. They might say that the evidence in this case is consistent but allow that it's inconsistent in other cases (e.g., cases where we compare a series of objects to see if they are of the same size or of different sizes). We needn't get too worked up about the details of this case provided that there is some case that the worldly internalists agree would be a case in which the evidence provided by experience is inconsistent.
} 
A familiar objection to Inconsistent Evidence is that the relevant conditional probabilities would be undefined when a thinker's total evidence were inconsistent (Williamson, 2009: 310). Remember that $e$ is evidence for $h$ when $P(h \mid e)>P(h)$, but given the ratio formula for conditional probability, $P(h \mid e)$ is undefined when $P(e)=0$.

Worldly internalists might complain that this objection is too quick. If God were to think of some number at random, the probability that God would think of 7 might be 0 . The probability that God is thinking of an odd number conditional on thinking of 7 is 1 . Reflection on such cases might make it seem that we need a better way of thinking about conditional probability, one that allows that $\mathrm{P}(h \mid e)$ might be welldefined even when $\mathrm{P}(e)=0$. We can do this if we treat conditional probabilities as primitive. $^{8}$

We don't think that the introduction of primitive probabilities gets to the heart of the problem even if it allows us to say that $\mathrm{P}(h \mid e)$ is well-defined when $\mathrm{P}(e)=0$. The problem is that $\mathrm{P}(h \mid e)$ is trivial or undefined when $e$ is contradictory. The problem has nothing per se to do with the fact that $P(h \mid e)$ can't be defined by the ratio $P(h \& e) / P(e)$ when $P(e)$ is 0 . Even in frameworks where $P(h \mid e)$ is well-defined when $P(e)$ is 0 , we still require that $P h \mid e)=1$ if $e$ entails $h$ (e.g., the conditional probability that God randomly chooses 7 given that God randomly chooses 7 is 1). Since inconsistent evidence entails everything it trivially supports everything. ${ }^{9}$

There is an additional worry. $P(\cdot \mid e)=P\left(\cdot \mid e^{\prime}\right)$ if $e$ and $e^{\prime}$ are logically equivalent. Any two inconsistent bodies of evidence are logically equivalent. So, if we wanted to say, for example, that the evidence we acquire by observing the Penrose display supports the hypothesis there is a figure with three sides in front of us, we'd have to say that every inconsistent body of evidence we might have had, regardless of the propositions it included, would also support that hypothesis, and support it to the same degree. That must be wrong. Had we acquired an inconsistent body of evidence by, say, looking at a visual illusion involving some four-sided object, we wouldn't want to say that this evidence likewise supported the hypothesis that the object we were viewing was three-sided. It is worth repeating Hájek's (2003: 285) warning that probability 0 and impossibility aren't the same thing. Even if we know how to model the evidential support provided by propositions that have probability 0 , we don't thereby know how to model evidential support provided by contradictions.

A referee for this journal asked whether it might help the worldly internalist to develop a theory of evidential support on which evidence supports $p$ only if we grasp or appreciates the entailment or probabilistic support between the supporting evidence and $p$. The advantage of such a view would presumably be that we would be freed from having to say that all inconsistent bodies of evidence support the same

\footnotetext{
${ }^{8}$ See Hájek (2003) and Popper (1959) for a discussion of primitive conditional probabilities and why we might not want to use the ratio formula to understand conditional probabilities.

9 Popper functions are such that if $e$ is contradictory $P(h \mid e)=1$ for every $h$.
} 
hypotheses since justifying support would require a grasp or appreciation of, say, an entailment between the evidence and a proposition and different thinkers might appreciate or grasp different entailment relations. We can see how this might help mitigate one problem that we want to avoid (i.e., that every inconsistent body of evidence would have to support the same things), but we think that it doesn't avoid a related problem. If a thinker knew that her evidence was inconsistent, she could thereby grasp that her evidence entailed every proposition that she grasped. If all it took to have such evidence is having inconsistent experiential contents, the worldly internalist would seem to be saddled with the unfortunate view that this thinker looking at the Penrose triangle would have evidence that supported her belief that the figure was three-sided, but also for thinking that any other proposition she grasped was true, assuming that she understood that everything follows from a contradiction. What would be needed to avoid the problems is something much more radical, a denial that known entailments between evidence and hypothesis sufficed for confirmation. We see this as a cost.

A related problem with Inconsistent Evidence is that it conflicts with an intuitive picture of evidential support, one that's much less committal than the probability raising conception. A thinker's evidence, at a time, rules out some possibilities and then tells the thinker how much confidence she ought to invest in the space of possibilities not eliminated by the evidence. If a thinker's evidence includes the three contradictory propositions, it will entail things that are rational to believe in the case, such as that there is a three-sided shape in front of you. Unfortunately, it also rules out these things, since it also entails their negations. Given Inconsistent Evidence, we cannot say both that your evidence supports $p$ when it entails $p$ and that it doesn't support $p$ when it rules $p$ out.

Finally, we should note that a thinker's evidence is generally taken to be that which the thinker should presuppose in formulating a decision problem. The states of the world that the thinker's evidence rules out can be ignored and the thinker can then distribute her degrees of confidence over the states that remain. These would be the states that were consistent with her total evidence. We don't know how to formulate a decision matrix that presupposes, say, that each proposition in an inconsistent set. What bets should we take about, say, the closeness of the lines if we have to assume that each side we focus on is closer than the others? We don't know how to answer these questions without imposing a consistency requirement on the evidence. ${ }^{10}$

At this point the worldly internalists might want to complicate the rules that relate inconsistent evidence to justified belief. They might say for instance that what

\footnotetext{
${ }^{10}$ We agree with Comesaña (2020b: 134) that in some cases where a thinker's attitudes are inconsistent, it's not clear what decisions would be rational to make, but we think that in some cases (e.g., the case discussed in the next section), it is reasonably clear that some bets would be rational to take and others wouldn't be. We thus want a view that says that in cases of inconsistent experiential contents, a thinker can have consistent evidence and that this consistent body of evidence favours some bets and not others. But we worry that worldly internalists cannot deliver this nuanced approach because it either allows for inconsistent evidence (in which case it's not clear how to distinguish the rational responses from the irrational ones) or it introduces some measure to ensure that evidence is consistent that faces problems of its own.
} 
one is justified in believing in the light of inconsistent evidence is given by what a subset of one's evidence (one's 'undefeated' evidence, perhaps) supports. These strategies are analogue to those that preserve a straightforward relation between evidence and justified belief but provide a consistent body of evidence in cases like ours. We'll see the problems they face below; the same problems arise for those that complicate the rules relating evidence and justification instead.

We know that those who flirt with the idea that there might be inconsistent evidence are open to the idea that when we have such evidence, we might not be able to say that anything is rational. ${ }^{11}$ We have some sympathy for this idea. After all, we don't see how to offer a sensible theory of evidential support when the body of evidence is logically equivalent to a contradiction. The thing that we want to say, though, is that we don't think that encountering a Penrose triangle or having a series of visual experiences with incompatible contents puts you in such an impossibly difficult situation. We think it's pretty clear that some responses are rational and others aren't. For instance, faced with a sculptural version of the triangle in which there is fact of the matter about which side is closer than the others it seems reasonable to bet $\$ 1$ against $\$ 1,000,000$ that the left side is closer than the bottom one, but not to take the same bet with opposite odds. This makes us highly suspicious of any view that describes our case (which, to us, seems like a boring case of known perceptual error) as an exotic case in which all the rules of rationality go out the window because the thinker is saddled with an inconsistent body of evidence. As we see it, they're saddled with an inconsistent set of experiential contents, not inconsistent evidence. That's a good reason to think that we shouldn't identify the subject's evidence with the inconsistent propositions. We see it a reason for thinking that if the worldly internalists are committed to Inconsistent Evidence, we should reject worldly internalism.

\subsection{If Inconsistent evidence is impossible}

To avoid these worries, the worldly internalists might take a different approach. They might try to show that they are not committed to the possibility of inconsistent evidence. Among other things, they would have to show that when we have inconsistent experiential contents, our evidence is nevertheless consistent. We think that they won't be able to provide a plausible account of when experiential contents constitute evidence and when they do not so as to avoid the difficulties discussed in the previous section without taking on further implausible commitments about which contents can constitute evidence. They would need to offer some account of the evidence we do get when some source tries to give us evidence that is collectively inconsistent. We think that they won't be able to vindicate our intuitions about what would be rational to believe in such cases.

If a thinker is in a situation in which some source of evidence tries to enter propositions into our evidence that would collectively be inconsistent (e.g., cases in

11 Comesaña (2020b: 134). 
which the contents of a series of visual experiences are inconsistent), they would have to choose one of these options:

(SOME) The thinker's evidence entails some of the jointly inconsistent propositions.

(MOST) The thinker's evidence entails that most of the jointly inconsistent propositions are true, without entailing any of them in particular. ${ }^{12}$

(NONE) The thinker's evidence doesn't entail that any of the jointly inconsistent propositions is true.

To understand the difference between these options, suppose some subject undergoes a series of experiences, the contents are $p_{1}, \ldots, p_{n}$, and these contents are inconsistent. In our cases, the subject is confronted with an apparent symmetry. There are no salient or available grounds for 'choosing' some of the propositions in the set over others to play the evidence role. What SOME says is that in spite of this, some specific propositions from this set constitute evidence and others are not. NONE tells us that each potential piece of evidence has equal standing. Since they cannot each constitute evidence, none of them constitute evidence. MOST tells us that more than half the propositions in this set constitute evidence without necessarily identifying specific propositions that belong to the thinker's evidence in the way that SOME does.

The obvious problem with SOME is that it amounts to picking winners and losers from the potential pieces of evidence vying to play the evidence role when such choices would seem completely arbitrary from the subject's perspective (Smith, 2021). In the absence of epistemically relevant internal differences between the propositions (e.g., in terms of strength of support, type of support, etc.), the view would suffer from the kinds of problems that beset externalist views. Given the setup, SOME clashes with the intuition that Huemer thinks provides the clearest motivation for internalism about epistemic rationality:

... there cannot be a pair of cases in which everything seems to a subject to be the same in all epistemically relevant respects, and yet the subject ought, rationally, to take different doxastic attitudes in the two cases-for instance, in one case to affirm a proposition and in the other to withhold (2006: 151).

If these differences in what's rational offend internalist sensibilities, it would seem that ungrounded differences between the propositions that do constitute evidence and those that do not should likewise seem problematic. Let's not forget that differences in evidence predict differences in what would be rational to believe.

We think that SOME is particularly implausible in cases like Penrose's triangle. In such a case, it seems that it wouldn't be rational to believe that the left side is closer than the bottom side, that the bottom is closer than the right, or that the right is closer than the left, so we don't think that it makes sense to say that we have

\footnotetext{
12 One version of MOST says that one's evidence consists in the disjunction of the maximal consistent subsets of the inconsistent set, for instance. That is, if one's experience delivers five jointly inconsistent propositions where any four of them are consistent, one's evidence is that four of these propositions are true.
} 
strong or entailing evidence to believe some but not all of these claims. In such a case, NONE seems quite tempting because it seems that none of the beliefs that might be supported by some consistent subset of the propositions are rational to hold but it seems that they should be if the subject's evidence included, say, the proposition that the left side is closer than the bottom side.

In cases like the Penrose triangle case, MOST seems highly implausible. We don't like the view that, say, the subject's evidence completely rules out, say, that the bottom side is closest (e.g., if it included the proposition that the left side was closer than the bottom and that the right side were closer than the left). Nor do we like the view that says that the subject's evidence entails that at least two of these propositions are true, without saying which. It seems a rational thinker could suspect that most or even all of these propositions are false and that's hard to square with MOST. $^{13}$

NONE is perhaps the most natural view to take in the Penrose triangle case, but it seems implausible in other cases:

Music Store. You're accompanying your cellist friend on a visit to the music store. She wants to test your knowledge of orchestral instruments. You gladly accept, as you've recently been learning about them. She points at various instruments and you confidently identify them as a flute, a French horn, a bassoon, a viola, and so on. She draws a tick or a cross on her notebook at each answer. At some point you catch a glimpse of the notebook and notice that one entry at least has a cross, not a tick. ${ }^{14}$

NONE strikes us as overly sceptical. One reason for this is that you shouldn't assume that if you're misidentified an instrument it's likely that you misidentified the others. For your abilities to identify the different instruments will differ (e.g., you might have used different visual features, learned from different webpages, etc.), so that there is little a priori reason to be confident that one is flawed if another is. It would thus be an overreaction to suspend in each case upon learning that one error was made. We think it's better for worldly internalists to say that either there are some relevant internal differences between the particular cases (e.g., you have more experience identifying oboes) or say that it's rational to believe each of the propositions in this case. NONE vindicates neither intuition.

\footnotetext{
13 That wouldn't be so if you could a priori work out (a) that the only way to build such a display is to have one side closest, the second further way, and the third even further away (b) that one's experience is unlikely to show all the angles backwards. (a) and (b) would make it a priori likely that one's experience is correct with respect to two angles. But (a) is false: one can build such a display with two or even three sides equally close. It should not be something that one should be a priori confident of.

14 Remember that worldly internalists disagree about what a thinker's visual evidence might be in this sort of case (e.g., it might be propositions about the look that some object has, the kind of thing some object is, or it might propositions be about what the subject sees to be true). The knowledge that at least one of these propositions is false is provided by the cross that indicates that an error was made. The inconsistency requires that the (apparent) fact that an error was made is part of your evidence. Someone might balk at this. We could have constructed an experiential preface case using collections of sticks where each pair seems to have the same length (e.g., when two are seen side by side) where the collection seems to involve sticks of different lengths (e.g., when they're held in a fist and all but one appears to have the same length).
} 
Not everyone shares our intuitions about cases like Music Store. Following Foley (2009: 44), we think that we can have knowledge in cases where we know we have inconsistent beliefs provided that the beliefs in isolation were good candidates for knowledge and the agent can reasonably expect that an error in one case isn't a sign of widespread error. Glancing at the notebook is arguably not enough to prevent one from knowing, say, that the flute is a flute. Even if one is unable to internally spot any relevant difference between one's belief about the flute and one's belief about the instrument one mistakenly takes to be a clarinet, it is still the case that one's belief about the flute has a different history and can meet various putative requirements for knowledge. And it'd be too sceptical to say that an unspecific defeater like the notebook's inscription is enough to prevent that belief to constitute knowledge. We can be pretty confident that at least one of our most confidently held beliefs is false and yet we don't think that none of them constitutes knowledge. If knowledge entails justification and if one's beliefs about the instruments are internally alike, internalists should then say that each of them is still rational.

We do think that MOST might vindicate our intuitions about cases like Music Store. Worldly internalists might take a leaf from the Lockean's book. On the Lockean view, it is rational to believe something iff it is rational for one to be highly confident that it is true (Foley, 2009). Given MOST, it is rational to be certain that most of one's identifications are correct. Given that one has no (internal) reason to favour one over another, for each identification one should be highly confident that it is correct. ${ }^{15}$ Thus, given MOST and Lockeanism, it is rational to believe each of the inconsistent propositions.

While this is promising, we worry that the worldly internalists won't have a principled basis for saying why NONE holds in some cases (e.g., the case of the Penrose triangle) and MOST holds in others (e.g., MUSIC STORE). Comesaña (2020b: 132-134) is the only worldly internalist to have confronted the problem of inconsistent evidence. He suggests that we introduce a justification filter on evidence: an experience as of $p$ provides $p$ as evidence only if the experience provides undefeated basic justification for believing $p$. Some defeat-like mechanism may then explain why the relevant beliefs have basic undefeated justification in one case but not the other. Comesaña doesn't identity such a mechanism but argues that doing so is tantamount to giving an account of "exogenous" defeat (i.e., an account of how learning something can remove something from one's evidence). ${ }^{16}$

An immediate upshot of this move is that the proposal undermines the evidentialist project of explaining justification or rationality in terms of evidential support. It suggests that instead of lacking justification because of a lack of evidence, we lack some specific evidence because of a lack of justification. That strikes us as a significant cost. Note also that none of your experiences in Music Store has the content that most of your identifications are correct, so while we can see how the justification filter can deliver NONE, we doubt whether it can deliver

\footnotetext{
15 If one has identified 20 instruments and one is certain that one correctly did so at least 15 times, and if all the identifications are on a par, one should be at least $3 / 4$ confident in each.

16 Comesaña (2020b: 142-146) says that this is a problem for everyone. We do not disagree.
} 
MOST. We further worry that an account of when and how experiences provide undefeated basic justification would readily extend to an account for non-basic justification as well, thereby rendering the evidence-based account of justification otiose. As our cases suggests, such an account may well turn on how likely (it is rational to think that) one's experiences are misleading given that one of them is. If these conditional credences do all the heavy lifting they can account for justified belief more generally. The question of which, if any, of the content of one's experiences count as evidence would seem epiphenomenal.

It is worth stressing that the cases considered here are not any sort of problem for classical internalists or externalists like Williamson. Given a view like $E=K$, the problem of inconsistent evidence cannot arise because $E=K$ respects the veridicality constraint and the truth is always consistent. Similarly, if we adopt a view on which evidence is not strictly speaking true or false (e.g., a view on which evidence is constituted by mental states or events), the problem of inconsistent evidence would not arise. ${ }^{17}$

Let's briefly recap. Worldly internalists deny that evidence must be true. We have argued that they face a kind of dilemma that arises when we think about inconsistent contents. We see no principled way for a defender of false evidence to rule out the possibility of inconsistent evidence. If they allow for it, they cannot offer a suitable account of evidential support. If they try to avoid the possibility of false evidence, they cannot provide a suitable account of how it is that sources like visual experience that might give us inconsistent contents might provide us with consistent evidence. We understand the attractions of worldly internalism. It seems to vindicate the idea that evidence is propositional and seems to account for intuitions about error cases that views like $\mathrm{E}=\mathrm{K}$ struggle with. Still, if the view cannot vindicate intuitions in cases of inconsistent contents and alternative views don't struggle with these cases, we think that this needs to be taken into account when choosing a theory of evidence.

\footnotetext{
17 What about Comesaña's point that he merely needs an account of exogenous defeat, which everyone needs anyway? $\mathrm{E}=\mathrm{K}$ theorists have a ready account of how one loses evidence: namely, when one loses knowledge. If they accepted that whether one knows is partly explained by whether one is justified, they would be required to reverse the evidentialist order of explanation too; but they typically do not accept that. The problem they face is to account for how learning, e.g., that the bartender reports that your drink has been spiked, destroys knowledge: since it is unclear which of the standard conditions on knowledge (other than justification) is affected, they may have to say that either you lacked knowledge all along or keep it afterwards. This might in turn generate judgements about justified belief that internalists find deeply counterintuitive, but $\mathrm{E}=\mathrm{K}$ theorists have learned to live with those. Classical internalists face at most a problem of exogenous defeat restricted to facts about one's experience (or the relevant subset of mental states that constitutes one's evidence). The problem arises if some experience indicates that you don't have experience you actually have. Some classical internalists will argue that the relevant part of one's mental states is transparent in a way that makes this impossible. (See Smithies (2019).) Others might argue that the mental state in question is still part of one's evidence in such cases, and either accept that this rationalizes a somewhat akratic set of beliefs (it seems to me that $p$, it seems to me that it doesn't seem to me that $p$ ) or accept some complicated rules that relate evidence to justification. Yet others might concede that they need exogenous defeat here but count it as an advantage of their view that they have a more straightforward explanation of defeat.
} 


\section{Evidence and updating}

Let's consider a second set of problems for the worldly internalist. The disagreement about the veridicality of evidence is a disagreement about whether falsehoods can play the role that evidence is meant to play. We think of evidence as the thing that occupies this role: it is what we ought to update our beliefs and credences on. We think false evidence does not play this role. ${ }^{18}$

If a thinker can be certain that evidence is true, updating on one's evidence is straightforward. It makes sense for them to treat $p$ as true upon acquiring it as evidence. A thinker's conditional credences on $p$ capture how likely they take various things to be on the assumption that $p$ is true. As Ramsey put it, we temporarily assume that $p$ is true, hence hypothetically adding it to our stock of beliefs, adjust our overall belief state accordingly, and consider what credence in various hypotheses are. Thus, if it is rational for them to treat $p$ as true upon acquiring $p$ as evidence, it is rational for them to adjust their credences to their previous credences conditional on $p$ upon acquiring $p$ as evidence: $P_{\text {new }}(\cdot)=P_{\text {old }}(\cdot \mid p)$. That is, they should follow the standard Bayesian conditioning rule. Suppose instead that our thinker isn't certain that evidence is true and thinks that some evidence might be false. They think that even if they are to acquire $p$ as evidence, $p$ might be true, but it might be false. Acquiring evidence would be, by the subject's lights, more like forming an opinion than learning that something is so. It is then unclear why they should plan to move to a doxastic state that treats $p$ as true upon acquiring $p$ as evidence. It is thus unclear in what sense the thinker should still update on their evidence. Moreover, if some evidence might be false, we don't see what would prevent a rational thinker from thinking that their own future evidence is liable to be false. It is unclear in what sense this rational thinker should still update on their evidence.

An example will illustrate our concern. Nate is going to forecast of an election result. You know that Nate is a good, albeit fallible, predictor. You put the likelihood that his forecast will be right at .9. Then you hear Nate forecast that that your candidate will win. It would strange to react by flatly believing that your candidate will win (i.e., treating it as now certain that the candidate will win and adjusting your other attitudes in light of this change). You thought that there was a chance that Nate's forecast was false. Nate's forecast itself didn't give you a reason to revise your opinion on that. At most, it seems, you can assume that Nate forecasts

\footnotetext{
18 As an anonymous referee reminded us, this is but one role that evidence is thought to play. Kelly (2014) notes that evidence plays a variety of roles beyond being that which justifies belief (e.g., something that rational thinkers respect, a guide to truth, a neutral arbiter) and we would add that it is also something that guides the actions of rational agents. We think that if inconsistent evidence is not wellsuited for the role that we focus on (i.e., that of justifying belief), it is not likely to be well-suited to play these other roles. As noted above, if we're given an agent's utility function but cannot say what the agent's rational degrees of belief might be once they take account of their evidence, we cannot say what would be rational for them to do when making decisions in the face of risk. Thus, we think that defenders of worldly internalism need to take seriously concerns about using their notion of evidence in a theory of rational belief if they aspire to show that their conception of evidence is well-suited for these further functions.
} 
that your candidate will win, and you should adjust your belief state in the light of that only. If the veridicality of evidence is rejected, the evidence we acquire is fallible in the way that Nate's predictions are. Should we still conditionalize on our evidence? If not, how should we update on our evidence if we deny the veridicality of evidence?

Let's work through a toy example. We spell things out in terms of the looks view, but it is easily adapted to address other worldly internalist views. Owing to a recent spell of isolation surrounded only by catalogues you now know that you are really good at identifying Farrow and Ball's paint colours by sight. We want to work out how confident you can rationally be in your beliefs about the wall's colour given a look at it. Here are the propositions to keep track of and some stipulations about the case:

- It is certain that the wall is either Mouse's Back $(m)$ or Whale's Breath $(w)$.

- It is certain that the wall will either have the look of Mouse's Back $(\mathrm{Lm})$ or the look of Whale's Breath $(L w)$.

- We use Ep for the proposition that $p$ is all the evidence you acquire upon seeing the wall. It is certain that one will have an experience in which the wall has the look of Mouse's Back or Whale's Breath. On the looks version of worldly internalism, that means that it is certain that either ELm or ELw will obtain.

The look of a wall is not an infallible indicator of colour. The catalogue warned us, but we knew this already. Under some lighting conditions, a wall painted in Mouse's Back or Whale's Breath mightn't look that way to you, so there might be a mismatch in the objective properties of the wall (i.e., it might be painted in Mouse's Back or have the look of Mouse's Back) even if owing to your visual experience you're disposed to believe $L w w$ because your experience is indistinguishable from one you would have under ideal viewing conditions when $w$ obtains.

When you get a good look at a wall under what would seem to be good viewing conditions, your conditional credence that the wall is Mouse's Back given that the wall has that look is quite high. The same holds for Whale's Breath. Let's say that your prior credence $P$ is such that $P(m \mid L m)=P(w \mid L w)=.9$. You are certain that when the room is revealed you will experience the wall as of having one of these looks. When you get a look at the wall, the colour strikes you as being a kind of grey-brown reminiscent of the fawny colour of the British field mouse. (The catalogue says that this is how we identify Mouse's Back.) On the looks view, you acquire $L m$ as your evidence, so ELm obtains. How confident should you now be that the wall was painted Mouse's Back?

The boring answer, which we expect you expect from us, would be .9. We would arrive at that answer is we were to say that when you acquire $L m$ as a new part of your evidence (i.e., when ELm obtains), your confidence in $m$ should update to match your prior confidence in $m$ conditional on $L m$. This answer assumes that your credences should be changed in line with this principle:

Conditionalize: Upon acquiring Lmas evidence (i.e., when ELm obtains), it is rational for you to adopt credences $P_{\text {new }}(\cdot)=P(\cdot \mid \mathrm{Lm})$. 
We don't think that this boring answer is defensible once we're not certain that evidence is veridical. For if we aren't certain that the veridicality of evidence holds, you may assign $P(L m \mid E L m)$ and $P(L w \mid E L w)$ something less than 1 . That is, prior to entering the room you would allow for some chance that you will experience the wall as looking Mouses's Back even if it does not in fact look that way. Let's go with .9. The problem is that as Schoenfield (2017) shows, you shouldn't think that updating in accordance with Conditionalize is the best way to respond to new evidence. There are other ways of responding to new evidence that have greater expected accuracy.

To see this, consider two procedures, $U$ and $U^{\prime}$, where the agent conforms to $U$ iff $P_{\text {new }}(\cdot)=P(\cdot \mid e)$ when Ee obtains and conforms to $U^{\prime}$ iff $P_{\text {new }}(\cdot)=P(\cdot \mid E e)$ when $E e$ obtains. (In our toy example, $e$ will either be $L m$ or $L w$.) We use the Brier score as our measure of inaccuracy. ${ }^{19}$ The inaccuracy of your credence in $\mathrm{Lm}$ are as follows for each procedure:

- If you conform to $U$, if $E L m$ obtains your new credence in $L m$ is $P_{\text {new }}(L m)=1$, so its inaccuracy is 0 if $L m$ and 1 if $\sim L m$. If $E L w$ obtains your new credence in $\mathrm{Lm}$ is 0 so its inaccuracy is 1 if $\mathrm{Lm}$ and 0 if $\sim \mathrm{Lm}$.

- If you conform to $U^{\prime}$, if $E L m$ obtains your new credence in $L m$ is $P_{\text {new }}(\mathrm{Lm})=.9$, so its inaccuracy is .01 if $L m$ and .81 if $\sim L m$. If $E L w$ obtains your new credence in $L m$ is $P_{\text {new }}(\mathrm{Lm})=.1$, so its inaccuracy is .81 if $\mathrm{Lm}$ and .01 if $\sim \mathrm{Lm}$.

The prior expected inaccuracy of your credence in $L m$ conditional on ELm is given by weighing those by $P(L m \mid E L m)$ and $P(\sim L m \mid E L m)$, and similarly for ELw. Given that $P(L m \mid E L m)=.9$, we have:

- If we conform to $U$, the expected inaccuracy of our new credence in Lm if ELm obtains is $.9 \times 0+.1 \times 1=.1$

- If we conform to $U^{\prime}$, the expected inaccuracy of our new credence in Lm if ELm obtains is $.9 \times .01+.1 \times .81=.09$.

Conditional on ELw, the expected inaccuracy of your credence in $L m$ is also .1 if you follow $U$ and .09 if you follow $U^{\prime}$. Either way, you should expect your credence in $L m$ to be more accurate if you follow $U^{\prime}$. The same holds for your future credence in $m$. And as Schoenfield (2017) shows, among the update procedures that fix your credences as a function of the evidence you acquire, the one that will maximize your overall expected accuracy if you are not certain that evidence is veridical is not $U$ but $U^{\prime}$. Thus, a thinker who values accuracy and is not certain that evidence is veridical should not regard conditionalizing on their evidence as the best response to their evidence.

The same holds if worldly internalists accept a more cautious update rule. They may suggest that if you think that that is .1 likely that your evidence is false, upon

\footnotetext{
19 The Brier score is commonly used to measure inaccuracy. It is given by the squared difference between your credence and a perfectly accurate credence at a world (i.e., one that assigns 1 to all truths and 0 to all falsehoods that you have credences in). Schoenfield's result holds for any measure of inaccuracy that meets the minimal 'strict propriety' condition that any probabilistic credence function maximizes expected accuracy by its own lights.
} 
acquiring evidence $e$ you should not treat $e$ as true, but rather think that things are .9 likely to be as if $e$ is true and a .1 likely to be as if $\sim e$ is true. That is:

Jeffrey-Conditionalize: Upon acquiring $L m$ as evidence (i.e., when ELm
obtains), it is rational for you to adopt credences
$P_{\text {new }}(\cdot)=P(\cdot \mid L m) \cdot P(L m \mid E L m)+P(\cdot \mid \sim L m) \cdot P(\sim L m \mid E L m) .{ }^{20}$

In other terms, when Ee obtains you should update by Jeffrey conditionalization on the partition $\{e, \sim e\}$ with weights $\{P(e \mid E e), P E \sim e \mid E e)\}$. The procedure agrees with $U \prime$ on the posterior credence you should assign to $L m$, and, under a defensible assumption, on the posterior credence you should assign to $m .^{21}$ But it differs from $U \prime$ on the credences you assign to ELm itself: if you conform to $U \prime$, you will become certain that it obtains if it does and certain that it does not obtain if it does not; on Jeffrey-Conditionalize, you remain uncertain that it obtains if it does and uncertain that it obtains if it does not. ${ }^{22}$ Thus your credence in ELm is guaranteed to be more accurate if you follow $U /$ rather than Jeffrey-Conditionalize. ${ }^{23}$

What lesson should we take from this? Suppose that we're right and it is rational for you to update in accordance with $U \prime$. That is, you should adopt a new credence distribution by setting our new credences to $P_{\text {new }}(\cdot)=P(\cdot \mid E L m)$ upon experiencing the wall as having a specific look and not to $P(\cdot \mid E L m)$. Note, however, that we've adopted a view on which $E L m$, not $L m$, constrains our posterior credences and so ELm has replaced Lm. Moreover, on the looks view, ELm is a true proposition: if you experience the wall as having look $m$ then ELm obtains. This true proposition is thus the thing that constrains our posterior credences. It is also the thing that will

\footnotetext{
${ }^{20}$ An anonymous referee for this journal suggested that we might consider a view on which the posterior probability we ought to assign to $p$ is a function both of the content of the evidence and the strength of the perceptual seeming that provides it. We think that this is an interesting idea worth exploring since something besides the content of the seeming determines how confident we can rationally be, so factoring the strength of the seeming into the determination of the rational posterior credence makes sense. The thing that we would note, however, is that so far as these seemings are not maximally strong, it would not make sense to conditionalize on the content if we're open go the idea that the relevant target proposition might be false and we think that we might be open to that idea if the relevant seeming is not maximally strong. Thus, while we like this idea of taking account of the strength of seeming, we do not think that it will help worldly internalists circumvent any of the difficulties discussed here, but it might help some classical internalists fill out the details of their view.

21 The assumption required is that whether your evidence indicates that $m$ is independent of whether you have it, namely $P(m \mid L m \& E L m)=P(m \mid L m)$ and $P(m \mid \sim L m \& E l m)=P(m \mid \sim L m)$.

22 Following Jeffrey-Conditionalize, your posterior credence in ELm if it obtains is $P(E L m \mid L m) \cdot P(L m \mid E L m)+P(\sim E L m \mid L m) \cdot P(\sim L m \mid E L m)$. Assuming you are not certain your evidence is veridical, $P(E L m \mid L m)<1$ or $P(\sim E L m \mid \sim L m)<1$ (or both), so $\mathrm{P}(E L \mathrm{~m} \mid L \mathrm{~m}) \cdot \mathrm{P}(L \mathrm{~m} \mid E L \mathrm{~m})<\mathrm{P}(L \mathrm{~m} \mid E L \mathrm{~m})$ or $\mathrm{P}(\sim E L \mathrm{ml} \sim L \mathrm{~m}) \cdot \mathrm{P}(\sim L \mathrm{~m} \mid E L \mathrm{~m})<\mathrm{P}(\sim \mathrm{Lm} \mid \mathrm{ELm})$, so $\mathrm{P}(E L \mathrm{~m} \mid L \mathrm{~m}) \cdot \mathrm{P}(L \mathrm{ml} \mid E L \mathrm{~m})+\mathrm{P}(\sim E L \mathrm{ml} \sim$ $L \mathrm{~m}) \cdot \mathrm{P}(\sim L \mathrm{~m} \mid E L \mathrm{~m})<\mathrm{P}(L \mathrm{~m} \mid E L \mathrm{~m})+\mathrm{P}(\sim L \mathrm{~m} \mid E L \mathrm{~m})=1$. We can use the same reasoning if ELW obtains instead.

23 A worse proposal would be to recommend updating by becoming certain both of $e$ and $E e$ when $E e$ obtains. That update, like $U$, is still less expectably accurate than $U^{\prime}$ when it comes to your credences in $e$. But worse, it would make you liable to Dutch books: prior to looking, you'd wage some money on your evidence being false $(E L m \& \sim L m \vee E L w \& \sim L w)$ but you could see that no matter what happens you'll become certain that it is true and pay out. For the same reason, you would violate a Reflection principle: your present positive credence in that proposition would differ from your expected future credence in it (namely, 0).
} 
constrain the way that we formulate our decision matrices if, say, we're offered some bets on the colour of the wall. Now it seems that we've come full circle. We've now identified a true proposition that played precisely the role that everyone had thought evidence played in our theory of confirmation, updating, and rational choice. Isn't it the thing that plays the evidence role? If so, haven't we found a good reason for thinking that it won't be a potential falsehood (i.e., $\mathrm{Lm}$ ) that plays that role?

Our argument rests on the assumption that you aren't certain that your evidence is veridical and that you assign some positive probability to the hypothesis that ELm obtains while Lm doesn't. Without this assumption, our objection wouldn't get off the ground. Fair enough. We see this as a reasonable assumption.

First, if there can be false evidence and $\mathrm{Lm}$ is the kind of thing that could be false evidence, we have some reason to expect that some rational thinkers will assign positive probability to $E L m \& \sim L m$. If there are good objections to the idea that evidence is veridical, for instance, we don't see why it would be irrational for one's credences to be such that $P(L m \mid E L m)<1$. Being philosophically informed should make such credences rational. Worldly internalists might reply that even though we should expect that in general evidence can be false, it is irrational to suspect that one's own future evidence will be false. But this attitude is unreasonable. It's unreasonable to think that everyone around us might have false evidence but remain certain that we'll never be like them in having false evidence.

Furthermore, a thinker may be forced to assign $P(L m \mid E L m)<1$ by the Principal Principle. By the worldly internalist's lights, ELm obtains in that case if one visually experiences the wall as having the look of $m$. But you might know that the objective chance that you'll visually experience the wall as having the look of $m$ when it does not. By the Principal Principle, you should assign this possibility non-zero credences, and thus assign non-zero credence to ELm\& $\sim \mathrm{Lm}$.

We think our objection stands. Once we agree that we update on true propositions, that such propositions constrain our degrees of belief, and that such propositions exclusively determine what would be rational to do given a set of values, we don't see why there should be any temptation to say that our evidence would be constituted by falsehoods like $L m$ or $m$. All the heavy lifting seems to be done by the true proposition ELm because it's the anchor for all the relevant conditional credences. So far, we see no reason to reject the veridicality of evidence, only good reasons to adopt updating procedures that make the reliance on ELm transparent.

This should further help us see off an argument against the veridicality of evidence inspired by Rescorla's (2021) discussion of misplaced certainty. His argument can be summarised like this:

(a) In some good case, it is rational to update by conditionalizing on some worldly proposition $p$.

(b) What is rational in the good case is rational in some bad case in which $p$ is false.

(c) If it is rational to update by conditionalizing on $p, p$ is part of one's evidence. 
Together (a)-(b)-(c) entail that $p$ is false evidence in the bad case. So, we're supposed to conclude that it is rational to become certain of something false in the bad case and this, in turn, is supposed to support the worldly internalist's rejection of the veridicality of evidence. However, our previous discussion shows that the argument just sketched is unstable. For once we allow for false evidence, we lose the case for (c), as our previous discussion shows. A better diagnosis is to reject (c) straightaway: in the Bad case, one's evidence makes it rational to become certain of $p$, but $p$ itself is not included in one's evidence. We spell it further in the next section. $^{24}$

\section{Worldly internalism and sceptical pressure}

Recall that one of the main selling points of worldly internalism is that it is supposed to be less susceptible to the sceptical concerns we might have about classical internalism:

It is agreed on all hands that, in the good case, Mary is very well justified in believing that there is a tomato in front of her. So, whatever reason she bases her belief on in the good case must be a strong one, one that makes her very well justified in the belief. Our worry is that the Phenomenalist's candidate for this reason - a fact about Mary's phenomenal state - just isn't a strong enough reason, if it is a reason at all (Comesaña \& McGrath, 2016: 997).

We can see why worldly internalists might think that tinkering with the precise description of our perceptual evidence doesn't get to the heart of the problems that face classical internalists.

The question that interests us is this. Why would worldly internalism fare better in accounting for the strength of our perceptual reasons and vindicating our nonsceptical outlook? The worldly internalists can say that part of our evidence might include propositions about our experiences, but they can deny that our evidence is constituted exclusively by such propositions. Some will say that the evidence that we have for believing we this object before us is a tomato is either the proposition that this is a tomato or the proposition that we see that this is a tomato. Surely this is stronger evidence for the belief that this is a tomato than any proposition about the conscious character of our experience or any of the other propositions that the classical internalist might identify with our evidence. Even if it were a weaker proposition, such as a proposition about the look that some object has, this looksproposition would at least be about the public properties of external objects and this seems to be a surer basis than anything that the classical internalist can offer.

We don't deny the immediate intuitive pull of the suggestion, but the points from the previous section should give us pause. To see why the dialectical situation doesn't clearly advantage the worldly internalists, it will be helpful to introduce four propositions into our discussion:

$\overline{24}$ That is consistent with Rescorla's own take on misplaced certainties (Rescorla, 2021, esp. §6.2, §8.2). 
- Let $p$ be the target proposition that this is a tomato.

- Let $V p$ be the proposition that obtains if you have a visual experience as of this being a tomato.

- Let $e$ be the total relevant evidence provided by your experience, whatever it is.

- Let $E e$ be the proposition that you have $e$ as your total evidence.

We take doubts about the adequacy of evidence to justify believing $p$ to be, as the above quotation indicates, doubts about the strength of support that the evidence provides. We can restate Comesaña and McGrath's concern this way. Classical internalists identify $e$ with $V p$, so they equate (1) with (2):

(1) A rational thinker can have a high prior credence in $p$ given $e: P(p \mid e)$ is high.

(2) A rational thinker can have a high prior credence in $p$ given $V p: P(p \mid V p)$ is high.

That is a problem because it's not clear what justifies the a priori trust in experience that (2) captures. It's as if the classical internalists have to say that perception justifies provided we can have a high prior $P(p \mid V p)$ but then struggle to find something interesting to say about why we should a priori think that $V p$ makes $p$ likely.

Worldly internalists do not shoulder this difficult explanatory burden since they deny that (1) and (2) are equivalent. Because they identify $e$ with some worldly proposition, they might seem to have an easier time of explaining (1). If $e$ is either $p$ or that I see that $p$, it obviously entails $p$ and it is not mystery why $P(p \mid e)$ should be 1. Even if $e$ doesn't entail $p$ because $e$ is some looks proposition, the worldly internalist might argue that we have better a priori reasons to believe that things that have the look of a tomato generally tend to be tomatoes that to believe that our visual experiences of tomatoes tend to be accurate.

The upshot is that if our rational degree of belief is determined by $P(p \mid e)$, distinct from $P(p \mid V p)$, worldly internalists are better placed than classical internalists to explain why a high degree of confidence in $p$ is rational and why we can be justified in believing $p$ when we have the right kind of experience.

The problem is that, as we've argued, worldly internalists should not think that our rational degree of belief upon receiving evidence $e$ is determined by $P(p \mid e)$. For unless it is a priori certain that $p$ is true if $E e$ obtains, our rational posterior credence in $p$ should match $P(p \mid E e)$ and not $P(p \mid e)$. Because of this, they face an explanatory challenge that classical internalists do not, which is to explain this:

(3) A rational thinker can have a high prior credence in $p$ given $E e: P(p \mid E e)$ is high.

Without an explanation of (3), it's not clear that worldly internalists are in a better position than classical internalists to explain how perception justifies a high credence in $p$. Worse, worldly internalists tend to assume that in such a scenario, Ee obtains just if $V p$ does. If that is so, we think it may be rational for you to be certain that it is: $(E e \leftrightarrow V p)=1$. And if it is, $P(p \mid E e)$ is high just if $P(p \mid V p)$ is high and the explanatory challenge that worldly internalists face is the same as the explanatory 
challenge that arises for classical internalism. How can worldly internalists address the challenge?

\subsection{First response}

The most straightforward response would be to say that a rational thinker should be a priori certain that their future evidence will be true. That is not inconsistent with the worldly internalist's view, since they can say that even though it is not true that all evidence is true, we are rationally required for us to assume that our future evidence will be true in spite of our philosophical knowledge that some evidence is false. ${ }^{25}$ However, as said above, it is hard to see how it could be reasonable for someone to think that the evidence of others and their own past evidence could be false and yet be completely certain that their future evidence won't be.

\subsection{Second response}

A more nuanced line of response might be to challenge Schoenfield's suggestion about how we ought to update when it's not a priori certain that our evidence is true. Perhaps the worldly internalists can live with the idea that it's rational for a thinker to knowingly revise their credences in ways that make them less accurate that they could otherwise do.

The difficulty with this response is that the problems discussed above arise for any view of how we ought to update when it's not certain that our evidence is true. Even if we don't endorse Schoenfield's particular proposal, we surely must take on board her point that in updating we need to be sensitive to considerations about how things might be if the evidence we think might be false is false. In doing so, we have to find a sensible value to assign to $P(p \mid E e)$. Moreover, worldly internalists and classical internalists can agree that you should be a priori certain that $E e$ iff $V p .^{26}$ If so, they still have no easier time explaining why that value should be high than the classical internalist has to explain why $P(p \mid V p)$ should be high, for given $P(E e \leftrightarrow V p)=1$ and account of the first is an account of the second.

\subsection{Third response}

A worldly internalist might explore one last avenue of response. They might say that while it is true (and perhaps even a priori certain) that facts about what evidence one has supervene on facts about what experience they have, it doesn't follow that $V p$ and $E e$ are a priori equivalent. By analogy, even if moral facts supervene on nonmoral facts, it doesn't follow that it is a priori certain moral facts obtain given certain non-moral facts because we might not know, say, whether utilitarianism is true. If it's not certain that $E e$ obtains iff $V p$ does, a rational thinker could in

\footnotetext{
25 See Das (2019) for a discussion of that combination of views.

${ }^{26}$ For classical internalists, $e$ is $V p$ and $\mathrm{E} e$ obtains just if $V p$ does. For worldly internalists, $e$ is a different proposition (such as $p$ itself) but $E e$ obtains in that scenario just if $V p$ does.
} 
principle assign different values to $P(p \mid E e)$ than to $P(p \mid V p)$, and it might in principle be easier to show that the former is a priori high.

We doubt that that is so, however. First, we don't see why a philosophically informed thinker could not realize that in that scenario $E e$ obtains just if $V p$ does; worldly internalists themselves routinely assume such identifications. We also think that it's worth thinking about the subject matter constraint that Comesaña appeals to in motivating worldly internalism. The worldly internalist might say that $e$ has worldly things as its subject matter (e.g., the existence of a tomato or its sensible properties), it doesn't seem that $E e$ has that subject matter. $E e$ is about the possession of $e$ as evidence. If Veridicality held, the proposition that $E e$ obtains would be about both worldly and mental things, but if Veridicality doesn't hold, Ee is really a proposition about the subject's mental life much in the way that $V p$ is. And since we've argued that the worldly internalists have to agree that you should update by setting your posterior credence in $p$ to a prior conditional credence that connects $p$ to some proposition about our mental lives that isn't world implicating, we find it completely obscure why they'd think that there is some advantage to be gained by telling thinkers on the one hand that they should set their new credence to $P(\cdot \mid E e)$ rather than $P(\cdot \mid V p)$ while telling them on the other that $E e$ and $V p$ are essentially about the same things, namely the subject's experiences (or attitudes in virtue of which they stand in certain relations to a proposition that might not be true).

We think this exhausts the responses available to the worldly internalists. We see no clear rationale for thinking that the worldly internalists enjoy a significant advantage over the classical internalists, particularly once we realise the important point about the update procedures that we ought to use in a setting in which the veridicality of evidence is rejected. Let's briefly return to a point from earlier in the discussion. We suggested that the cognitive scientist's discovery argument should make us somewhat sceptical that when we have two views that agree that our evidence supervenes upon our non-factive mental states, one view would gain a serious advantage over the other just by identifying our evidence with propositions about the external world instead of propositions about ourselves. We think we can make this worry more precise now. The sceptical worry about the sufficiency of the classical internalist's evidential base is the worry that if $e$ is $V p$, it doesn't justify belief in $p$. If justification is understood in terms of sufficient strength of support, this comes to the claim that $P(p \mid V p)$ is too low. But remember that if the internalist supervenience thesis is true, $V p$ iff $E e$. If the internalist supervenience thesis is known, shouldn't all internalists accept that the chance of being wrong about $p$ if $V p$ or if $E e$ are the same?

\section{Conclusion: evidence and reasons}

While we have tried to show that classical internalism with its commitment to Veridicality compares favourably to worldly internalism with its false evidence, we have had little time to discuss the motivating considerations that lead people to believe in false evidence. 
We think that one motivating might be this. People generally believe that there can be false, rational beliefs and that such beliefs can properly figure in reasoning. The false contents that figure in such reasoning might be the subject's reason for drawing a conclusion, making a decision, or performing an action. These beliefs, decisions, or actions might be rational, so it seems that these false contents might be both the subject's reason and a good reason. In the case of belief, don't we think that good reasons to believe just are pieces of evidence? So, if we accept false reasons, don't we have to accept false evidence?

This is very sketchy, but we think it captures an important and intuitive rationale for rejecting the veridicality of evidence. The main response to this kind of argument has been to challenge this idea that there might be false reasons. ${ }^{27} \mathrm{We}$ don't want to do that here. What we want to suggest is that there might be false reasons even if there cannot be false evidence.

Think for a moment about how some familiar pragmatic encroachers think about reasons, justification, and knowledge. ${ }^{28}$ They say that we rationally believe $p$ when we have knowledge-level justification to believe $p$ and typically say three things about believing with knowledge-level justification that $p$. The first is that we can have knowledge-level justification to believe falsehoods. The second is that we can have knowledge-level justification to believe things without having maximally strong support for that belief. The third thing is that when we have this justification for believing $p$, we have justification to treat $p$ as a reason in practical or theoretical reasoning. It is, under these conditions, a false reason. The pragmatic encroachers do not think that it follows that $p$ is also a piece of evidence. Think about the familiar bank cases. Let $p$ be the proposition that the bank is open. In the low-stakes case, the agent can know and rationally believe $p$ and $p$ will be a reason that counts in favour of, say, coming back to the bank tomorrow when the lines aren't so bad. In the high-stakes setting (e.g., where the rent is due, the bank might not be open tomorrow, and the rent won't get in on time unless the money is transferred by Saturday night), the badness of waiting if $\sim p$ were to turn out to be the case is supposed to explain why the agent doesn't have sufficient support for believing $p$. Under these conditions, $p$ wouldn't be a reason for the agent to come back tomorrow. The set of reasons for believing and doing things changes between the high-stakes case and the low-stakes case. What doesn't change, according to the standard pragmatic encroacher's view, is the level of evidential support the thinker has for believing $p$. The strength of evidential support for believing $p$, on the usual telling, is the same in the low-stakes and high-stakes case. The adequacy of that support, however, changes with changes in the stakes of being wrong about $p$. When there's adequate support, $p$ is one of the justifying reasons that the agent possesses that can justify acting and believing. Without it, it isn't.

Notice that if the evidential support for believing $p$ is the same in the low-stakes and high-stakes case, the evidence wouldn't include $p$ in either case. Were the subject's evidence to include $p$, her evidence would provide maximal support in

\footnotetext{
27 See Alvarez (2010) for defence of the view that all reasons have to be facts or true propositions.

28 What we say here applies most clearly to the views defended in Fantl and McGrath (2009).
} 
both cases, but in neither the low-stakes nor high-stakes setting does the pragmatic encroacher think that the agent has maximal support for that belief. So, they seem to think that we have one set of propositions that constitutes justifying reasons that can change its composition with changes in stakes and another set of propositions that constitute the evidential support for these propositions that constitute the evidence. ${ }^{29}$ The composition of this set doesn't change with changes in stakes. On this way of formulating the pragmatic encroacher's view, the propositions that constitute justifying reasons needn't be identified with the propositions that constitute the subject's evidence.

We can see why a classical internalist might have the view that there might be false justifying reasons even if there cannot be false evidence. The picture is one according to which we have two books, a book that contains all the propositions that constitute evidence and determine the strength of support and a book that contains a body of justifying reasons that are the objects of full belief, figure in practical and theoretical reasoning, and can contract when the stakes change but the evidence remains the same. Once we buy into this picture, we can see that sets of reasons might have properties that bodies of evidence do not. The pragmatic encroacher's theory, normally, is that we should be impurists about the conditions under which a proposition belongs to the set of justifying reasons but purists about the conditions under which a proposition constitutes evidence. So, perhaps they might be open to the idea that while the justifying reasons might contain falsehoods, the evidence does not. We can think of the evidence as the fixed certainties that don't change with changes in the practical stakes and cannot contain any falsehoods and that doesn't commit us to the view that there cannot be false reasons. That, however, just shows that arguing for the existence of falsehoods that properly figure in reasoning because they're the objects of rational full belief should not compel us to accept that there can also be falsehoods that belong to a thinker's evidence.

Open Access This article is licensed under a Creative Commons Attribution 4.0 International License, which permits use, sharing, adaptation, distribution and reproduction in any medium or format, as long as you give appropriate credit to the original author(s) and the source, provide a link to the Creative Commons licence, and indicate if changes were made. The images or other third party material in this article are included in the article's Creative Commons licence, unless indicated otherwise in a credit line to the material. If material is not included in the article's Creative Commons licence and your intended use is not permitted by statutory regulation or exceeds the permitted use, you will need to obtain permission directly from the copyright holder. To view a copy of this licence, visit http:// creativecommons.org/licenses/by/4.0/.

\section{References}

Alvarez, M. (2010). Kinds of reasons. Oxford University Press.

Arnold, A. (2013). Some evidence is false. Australasian Journal of Philosophy, 91, 165-172.

Bird, A. (2007). Justified judging. Philosophy and Phenomenological Research, 74, 81-110.

BonJour, L. (1985). The structure of empirical knowledge. Harvard University Press.

Brown, J. (2018). Fallibilism: evidence and knowledge. Oxford University Press.

\footnotetext{
${ }^{29}$ It is only in the most recent literature that there has been some discussion of the possibility of pragmatic encroachment effects on credences. See Gao (2019) for discussion.
} 
Brueckner, A. (2009). E=K and perceptual knowledge. In P. Greenough \& D. Pritchard (Eds.), Williamson on knowledge (pp. 5-11). Oxford University Press.

Christensen, D. (2004). Putting logic in its place. Oxford University Press.

Cohen, S. (1984). Justification and truth. Philosophical Studies, 46, 279-295.

Comesaña, J., \& Kantin, H. (2010). Is Evidence knowledge? Philosophy and Phenomenological Research, 80, 447-454.

Comesaña, J., \& McGrath, M. (2016). Perceptual reasons. Philosophical Studies., 173, 991-1006.

Comesaña, J. (2015). Falsehood and entailment. Philosophical Perspectives, 29, 82-94.

Comesaña, J. (2020a). A plea for falsehoods. Philosophy and Phenomenological Research, 100, 247-276.

Comesaña, J. (2020b). Being rational and being right. Oxford University Press.

Conee, E., \& Feldman, R. (2004). Evidentialism. Oxford University Press.

Das, N. (2019). Accuracy and Ur-prior conditionalization. Review of Symbolic Logic, 12, 62-96.

Das, N. Forthcoming. The value of biased information. British Journal for the Philosophy of Science.

Drake, J. (2018). Motivating reason to slow the factive turn. In V. Mitova (Ed.), The factive turn (pp. 177-93). Cambridge University Press.

Easwaran, K., \& Fitelson, B. (2015). Accuracy, coherence, and evidence. In T. Gendler \& J. Hawthorne (Eds.), Oxford studies in epistemology (Vol. 5, pp. 61-96). Oxford University Press.

Fantl, J. (2015). What is it to be Happy that P? Ergo, 2, 267-297.

Fantl, J., \& McGrath, M. (2009). Knowledge in an uncertain world. Oxford University Press.

Foley, R. (2009). Beliefs, degrees of belief, and the lockean thesis. In F. Huber \& C. Schmidt-Petri (Eds.), Degrees of belief (pp. 37-47). Springer.

Fratantonio, G., \& McGlynn, A. (2018). Reassessing the case against evidential externalism. In V. Mitova (Ed.), The factive turn (pp. 84-102). Cambridge University Press.

Gao, J. (2019). Credal pragmatism. Philosophical Studies, 176, 1595-1617.

Hájek, A. (2003). What conditional probability could not be. Synthese, 137, 273-323.

Hasan, A. (2011). Classical foundationalism and Bergmann's dilemma for internalism. Journal of Philosophical Research, 36, 391-410.

Huemer, M. (2006). Phenomenal conservatism and the internalist intuition. American Philosophical Quarterly, 43, 147-158.

Ichikawa, J. J. (2014). Justification is potential knowledge. Canadian Journal of Philosophy, 44, 184-206.

Kelly, T. (2014). Evidence. In E. N. Zalta (Ed.), The Stanford Encyclopedia of Philosophy. Stanford University.

Kiesewetter, B. (2017). The normativity of rationality. Oxford University Press.

Leitgeb, H. (2017). The stability of belief. Oxford University Press.

Littlejohn, C. (2012). Justification and the truth-connection. Cambridge University Press.

Littlejohn, C. (2013). No evidence is false. Acta Analytica, 28, 145-159.

Lord, E. (2018). The importance of being rational. Oxford University Press.

Makinson, D. C. (1965). The paradox of the preface. Analysis, 25, 205-207.

Mantel, S. (2018). Determined by reasons: A competence account of acting for a normative reason. Routledge.

McCain, K. (2012). The interventionist account of causation and the basing relation. Philosophical Studies, 159, 357-382.

McCain, K. (2014). Evidentialism and epistemic justification. Routledge.

McGrath, M. (2018). Looks and perceptual justification. Philosophy and Phenomenological Research, 96, $110-133$.

Mitova, V. (2015). Truthy psychologism about evidence. Philosophical Studies, 172, 1105-1126.

Neta, R. (2018). Your evidence is the set of facts that are manifest to you. In V. Mitova (Ed.), The factive turn (pp. 32-50). Cambridge University Press.

Popper, K. (1959). The logic of scientific discovery. Basic Books.

Pryor, J. (2000). The skeptic and the dogmatist. Noûs, 34, 517-549.

Rescorla, M. (2021). On the proper formulation of conditionalization. Synthese, 198, 1935-1965.

Rizzieri, A. (2011). Evidence does not equal knowledge. Philosophical Studies, 153, 235-242.

Ryan, S. (1991). The preface paradox. Philosophical Studies, 64, $293-307$.

Schellenberg, S. (2018). The unity of perception. Oxford University Press.

Schroeder, M. (2008). Having reasons. Philosophical Studies, 139, 57-71.

Schroeder, M. (2021a). Reasons first. Oxford University Press.

Schroeder, M. (2021b). Perceptual reasons and defeat. In J. Brown \& M. Simion (Eds.), Reasons, justification, and defeat (pp. 269-285). Oxford University Press. 
Schoenfield, M. (2017). Conditionalization does not (in general) maximize expected accuracy. Mind, 126, 1155-1187.

Shaffer, M. (2015). Approximate truth, quasi-factivity, and evidence. Acta Analytica., 30, 249-266.

Silins, N. (2005). Deception and evidence. Philosophical Perspectives, 19, 375-404.

Smith, M. (2016). Between probability and certainty. Oxford University Press.

Smith, M. (2021). Against legal probabilism. In Z. Hoskins \& J. Robson (Eds.), The social epistemology of legal trials (pp. 92-106). Routledge.

Smithies, D. (2019). The epistemic role of consciousness. Oxford University Press.

Unger, P. (1975). Ignorance. Oxford University Press.

Wedgwood, R. (2002). Internalism explained. Philosophy and Phenomenological Research, 65, 349-369.

Williamson, T. (2000). Knowledge and its limits. Oxford University Press.

Williamson, T. (2009). Replies to critics. In P. Greenough \& D. Pritchard (Eds.), Williamson on knowledge (pp. 279-385). Oxford University Press.

Worsnip, A. (2016). Belief, credence, and the preface paradox. Australasian Journal of Philosophy, 94, $549-562$.

Publisher's Note Springer Nature remains neutral with regard to jurisdictional claims in published maps and institutional affiliations. 